\title{
Treatment with Cisapride of the Gastrointestinal and Urological Sequelae of Spinal Cord Transection: Case Report
}

\author{
M. Etienne, ${ }^{1}$ M. Verlinden ${ }^{2}$ A. Brassinne ${ }^{1}$ \\ ${ }^{1}$ Hopital de Bavière, University of Liège, Department of Gastroenterology, \\ Boulevard de la Constitution 66, 4020 Liège and 2 Fanssen Pharmaceutica n.v., \\ Clinical $R$ E D Department, Turnhoutseweg, 30, 2340 Beerse, Belgium.
}

\section{Summary \\ We describe the case of a paraplegic patient who suffered traumatic spinal cord injury at the level of the twelfth thoracic vertebra. Within a short period of time following the injury, urinary (neuropathic bladder) and gastrointestinal (atonic colon) sequelae arose. Treatment with Cisapride ( $R 51$ 619, fanssen Pharmaceutica) was undertaken in an attempt to increase colonic motility and to reduce urinary retention. These goals were reached rapidly with a dose of $10 \mathrm{mg}$ q.i.d.; the effect has been maintained for at least 18 months since starting the therapy.}

Key words: Paraplegia; Atonic colon; Neuropathic bladder; Cisapride.

Spinal cord injury may result in neuropathic bladder dysfunction with hypertonicity of the external and/or internal sphincter and consequent urinary retention, and with absent sensation of bladder filling. In addition, colon motility is altered. Patients have severe constipation and often painful abdominal cramps.

\section{Case report}

Mr G.A., aged 57, sustained spinal cord trauma in 1976, with a fracture of $T_{11}$ and $L_{3}$ vertebrae and hyperesthaesia in the $\mathrm{T}_{12}$ area, hypoesthaesia at $\mathrm{L}_{1}$ level, anaesthaesia from the below $\mathrm{L}_{2}$, as well as a flaccid paraplegia. The ensuing neuropathic bladder necessitated two sphincterotomies (1981 and 1984) and numerous antibiotic courses with Amikacin to combat urinary infections. Medical treatment consisted of nitrofurantoin, diazepam, oxazepam + hyoscin-N-butylbromide, bisacodyl $5 \mathrm{mg}$ p.o. when needed, and one suppository of bisacodyl $10 \mathrm{mg}$ every other day. Since 1983 the patient experienced (especially posprandial) cramp like left fossa iliaca pain, subsiding after taking of antispasmodics or after the expulsion of intestinal gas or faeces. Defaecation only occurred after rectal administration of bisacodyl and did but partially relieve the pain. Occasional faecal incontinence during the day persisted. Aggravation of the pain and deterioration of bowel habits necessitated hospitalisation in October 1985.

Neither clinical examination nor diagnostic tests revealed any abnormalities of cardio- 
vascular or of pulmonary function, and liver and spleen volumes, blood chemistry and thyroid function $\left(\mathrm{fT}_{3}, \mathrm{fT}_{4}, \mathrm{TSH}\right.$, thyroglobulin) were normal. Oesophagogastroscopy was negative, and endoscopy and a barium enema showed no relevant colonic or rectosigmoidal lesion. The neurological picture was dominated by atrophy of the lower extremities, and the same sensory changes that were found in 1976. Intestinal peristalsis was audible, and digital examination of the rectal ampulla disclosed hypertonicity of the external anal sphincter and an empty rectum.

Stasis of faecal material occurred at $38 \mathrm{~cm}$ of the anal verge, and the colon, and in particular the descending colon, was markedly dilated. Residual urine amounted to approximately $100 \mathrm{ml}$. Since gastrointestinal stenosis had been excluded, the patient was begun on Cisapride, $10 \mathrm{mg} 4$ times daily (20 to 30 minutes before meals and before retiring) while antispasmodic agents as well as oral laxatives were withdrawn. Cisapride is a novel therapeutic agent, devoid of direct cholinergic or dopaminolytic properties, which enhances motility by selectively increasing the amount of acetylcholine that is released from the postganglionic cholinergic nerve endings in the Auerbach plexus (Reyntjens et al., 1986; Schuurkes et al, 1985). Clinical trials have suggested the drug's effectiveness in the treatment of chronic functional constipation (Muller-Lissner et al, 1987; Verlinden et al., 1986).

Less than 1 week after the start of the Cisapride administration, the abdominal pain disappeared completely. Stools of normal consistency were passed every other day after the administration of a suppository of bisacodyl. The patient was very impressed with the result and did not recall having passed stools so satisfactorily since the traumatic event. After 1 month of therapy, withdrawal of bisacodyl suppositories was attempted. However, within 24 hours, bouts of abdominal pain resumed and defaecation became exceedingly difficult. Hence, 9 days later therapy with rectal bisacodyl was restored, immediately resulting in a return to the previous favourable situation.

Two months after the start of the Cisapride treatment, $\mathrm{x}$-ray examination demonstrated the existence of sphincteric hypertonia, but bladder emptying was satisfactory. On cytoscopy, the bladder had a trabecular appearance and the bladder neck was opened. The sphincter remained spastic but wide. There was no significant urinary residue, indicating satisfactory vesicular emptying during the Cisapride treatment. This result was obtained without any other corrective measures.

The patient was discharged from hospital and was maintained on the following therapeutic regimen: flunitrazepam ( $2 \mathrm{mg}$ nocte), diazepam ( $5 \mathrm{mgr}$ t.i.d.), Carbobel (1 tablet containing $200 \mathrm{mg}$ of carbon and $40 \mathrm{mg}$ of hexamethylene-tetramine b.i.d.), Cisapride (10 mg q.i.d.) and bisacodyl (one suppository every other day).

Eighteen months after the start of the Cisapride therapy, the patient was seen for follow-up. The good clinical result has been maintained and the patient rated the therapeutic result as excellent.

Consistency of the stools had markedly improved, the bowels were evacuated in a single attempt, and faecal incontinence and abdominal pain had disappeared. The postmicturition urinary residue had been reduced to normal values. At present the therapy is maintained at $10 \mathrm{mg}$ of Cisapride, administered 4 times daily.

\section{Conclusion}

Our observations indicate that the relief was the result of the combined therapy of Cisapride and laxative suppositories. Ideally, the gastrointestinal complaints in paraplegia should be solved without resorting to laxatives. Hence, we suggest that Cisapride (in a dose of $10 \mathrm{mg}$ q.i.d.) is prescribed at the very onset of digestive symptoms.

Moreover, such a treatment may also be beneficial for the functioning of the neuropathic bladder. It could reduce the frequency and severity of urinary infections because of a reduction of the residual bladder urine. 


\section{References}

MULLER-LISSNER SA and the Bavarian constipation study group 1987 Treatment of chronic constipation with cisapride and placebo. Gut 28(8):1033-1038.

REYNTJENS A, VERLINDEN M, AERTS T 1986 Development and clinical use of the new gastrointestinal prokinetic durg cisapride (R 51 619). Drug Development Research 8:251-265.

Schuurkes JAJ, Van Nueten JM, Van Daele PGH, Reyntjens AJ, Janssen PAJ 1985 Motorstimulating properties of cisapride on isolated gastrointestinal preparations of the guinea pig. fournal of Pharmacology and Experimental Therapeutics 234:775-783.

Verlinden M, Schiettekatte L, Demyttenaere P, Vervaeke M, Goyvaerts H, Reyntjens A 1986 The effect of chronic administration of 5 and $10 \mathrm{mg}$ of cisapride on moderate idiopathic constipation: a Belgian dose-response trial. Digestion 34:157. 